\title{
DEZ ANOS DOS ÍNDIOS TERENA EM MATO GROSSO: APRENDIZAGENS DE UM PROCESSO MIGRATÓRIO, CONQUISTAS E DESAFIOS
}

ALCEU ZOIA ${ }^{1}$

UNEMAT

JAQUELINE PASUCH ${ }^{2}$

UNEMAT

ODIMAR JOÃO PERIPOLLI ${ }^{3}$

UNEMAT

\begin{abstract}
RESUMO: Este artigo tem como objetivo refletir a respeito do processo migratório da etnia indígena Terena após a expulsão de suas terras no Mato Grosso do Sul e a consequente chegada à nova terra, no Mato Grosso. Pretende-se destacar as aprendizagens construídas na trajetória de lutas, apontar algumas conquistas e desafios que este povo vem enfrentando nesses dez anos para se reconstituir enquanto povo indígena. A conquista da terra de um "assentamento indigena" se coloca como fator determinante frente aos desafios que se fazem sentir: a pressão exercida pelo projeto do capital, no caso das tentativas de ocupação das terras, e o resgate ao modo de ser terena, que durante o processo migratório se entrelaçou com outras culturas e não permitiu que uma geração de crianças e jovens a identificassem como sua etnia específica. Esse desafio se coloca também à escola, pois esta desempenha um papel importante dentro do assentamento indígena, como um espaço de encontros entre os diferentes sujeitos, culturas e saberes. As conquistas e os avanços não garantem direitos já adquiridos, dai sinalizarem para novos desafios. Estes índios aprenderam durante o processo migratório que os direitos se consolidam na luta.
\end{abstract}

PALAVRAS-CHAVE: educação indígena; povo terena; processo migratório.

ABSTRACT: This article aims to reflect about the migration process of the Terena indigenous

\footnotetext{
${ }^{1}$ Professor Doutor da Universidade do Estado de Mato Grosso (UNEMAT), atua no PPGEdu em Cáceres-MT e é professor adjunto do Departamento de Pedagogia do Campus Universitário de Sinop, onde realiza pesquisas no grupo Educação e Diversidade no Contexto da Amazônia Legal Matogrossense. E-mail: alceuzoia@hotmail.com.

${ }^{2}$ Professora Doutora da Universidade do Estado de Mato Grosso (UNEMAT), atua no PPGEdu em Cáceres-MT e é professora adjunta do Departamento de Pedagogia do Campus Universitário de Sinop, onde realiza pesquisas no grupo Educação e Diversidade no Contexto da Amazônia Legal Matogrossense. E-mail: jaquep@terra.com.br.

${ }^{3}$ Professor Doutor da Universidade do Estado de Mato Grosso - UNEMAT, atua no PPGEdu em Cáceres-MT e é professor adjunto do Departamento de Pedagogia do Campus Universitário de Sinop, onde realiza pesquisas no grupo Educação e Diversidade no Contexto da Amazônia Legal Matogrossense. E-mail: ojperipolli@gmail.com .
} 
people after the expulsion from their land in Mato Grosso do Sul State, and the consequent arrival to a new land, in Mato Grosso State. It is intended to highlight the knowledge produced in the path of struggle, point out some achievements and challenges that this nation has faced in those ten years to reconstitute themselves as an indigenous group. The conquest of an "Indian settlement" is placed as a determining factor before the presented challenges: the pressure exerted by the capital project, in the case of the attempted occupation of the lands, and the rebuilding of the Terena way of life, which during the migration process was intertwined with other cultures, not allowing new generations to identify themselves with a specific ethnicity. The school also faces this challenge, since it plays an important role within the indigenous settlement, as a space of encounters between the different subjects, cultures and knowledges. The achievements and advances do not guarantee acquired rights, hence signaling to new challenges. These indians learned during the migration process that rights are consolidated by the fight.

KEYWORDS: indigenous education; terena people; migration process.

\section{Introdução}

A luta pela terra do povo Terena é longa. Relembrando a história, percebemos que esse povo, que lutou na Guerra do Paraguai (18641870) e que foi um dos grupos que se aliaram ao Exército Brasileiro, é lembrado pelo escritor Visconde de Taunay (1843-1899) como "índios mansos, amigos, aliados". Esse envolvimento dos Terena com o Exército Brasileiro se estendeu até a Segunda Guerra Mundial, quando vários deles lutaram na Europa como pracinhas da Força Expedicionária Brasileira. No entanto, apesar dos vários registros na história brasileira, os fazendeiros da região continuam afirmando que os Terena não pertencem ao território brasileiro e, assim, negam sua identidade.

O povo Terena contribuiu muito para a formação da região sulmato-grossense; no entanto, é pouco lembrado pelos seus feitos. Cardoso de Oliveira (1976) destaca o papel das mulheres Terena nesse processo, especialmente aquelas que viveram como esposas dos primeiros moradores da região. Porém, apenas os mais ilustres ficaram para a história, como o caso do Marechal Rondon, que teria tido uma avó Terena, assim como o comandante geral das fronteiras com o Paraguai, o senhor Ricardo Franco de Almeida Serra e também o 
Visconde de Taunay, homens que também teriam vivido com índias Terena.

Atualmente, a presença dos Terena no Estado de Mato Grosso do Sul é constante e percebe-se, historicamente, que este povo sempre buscou uma aproximação com os não índios. É o grupo com maior população fora de aldeias - 9,6 mil índios, correspondendo à quinta maior etnia do país, com 29 mil integrantes, segundo levantamento do Instituto Brasileiro de Geografia e Estatística (IBGE). Somente na capital, Campo Grande (MS), há sete "aldeias urbanas", áreas com maior concentração da etnia. Ali, é comum vê-los executando diversas atividades remuneradas, trabalhando principalmente em frigoríficos.

Há muitos anos percebemos que um diferencial do povo Terena é o intenso contato com o mundo não indígena e a aliança com outros povos. Apesar disso, conseguem manter seus elementos culturais mais fortes, como a língua, a dança e a atividade agrícola. Em nossas pesquisas, na região norte de Mato Grosso, isso também pode ser percebido. Encontramos, vivendo com os Terena, diversos índios de aldeias vizinhas que aproveitam da hospitalidade desse povo para, principalmente, frequentar a escola, melhor equipada nessa comunidade.

\section{A origem da migração}

Criou-se na maioria da população, que é não-índia, a ideia de que os índios não precisam dessas terras, que deveriam se contentar com suas reservas e as cestas básicas dadas pelo governo. É, na verdade, a continuidade, a perpetuação da ideia primeira dos portugueses e espanhóis que aqui chegaram e passaram por cima das milhares de criaturas que eles acreditavam não ter alma por não falarem sua língua nem viverem da mesma maneira que os europeus (TAVARES, 2013, n.p.).

Ao tratar sobre a colonização, Cardoso de Oliveira (1968) destaca três ciclos fundamentais que aconteceram durante o processo de ocupação e povoamento da região sul do Mato Grosso, hoje o Estado do Mato Grosso do Sul. Tais ciclos foram progressivamente expondo a 
população indígena ao contato de modo cada vez mais intenso com a sociedade não índia e com o modo de produção capitalista que começava a ser introduzido em suas terras.

O primeiro dos ciclos ou a primeira tentativa de ocupação econômica desta região, onde hoje é o Estado do Mato Grosso do Sul, ocorreu por volta dos anos de 1830, menos de um século depois da chegada dos Terena em solo brasileiro. Esta etapa inicia-se com a vinda de segmentos pastoris da sociedade nacional, vindas do "Triângulo Mineiro", que se deslocaram para esta região com a finalidade de criar gado de modo extensivo, não impondo limites às pastagens ou fronteiras para as propriedades. $O$ gado ia se deslocando conforme a oferta de pastagens, prática que, até certo ponto, interferiu no processo de "fixação" da população nacional nos ermos mato-grossenses que ainda não se daria nesta oportunidade, devido à própria natureza da economia pastoril.

Conforme documentou Cardoso de Oliveira (1968), o tipo de atividade econômica que começou a ser desenvolvido na região sul do Estado de Mato Grosso estava baseada na criação extensiva de gado e não forneceu condições para permanência de contingentes populacionais naquelas áreas, demandando apenas de alguns trabalhadores rurais para a lida campeira 4 . Iniciou-se, portanto, um processo de exploração econômica do espaço, isso sem a colonização de fato da área e sem a permanência da população nesse lugar considerado tão distante da "civilização".

O segundo ciclo do processo de ocupação pode ser qualificado como sendo um ciclo de povoamento, ocorrendo após a Guerra do Paraguai $^{5}$, e como resultado da desmobilização do exército brasileiro, que após o término da Guerra passaram a se instalar nesta região. De modo significativo, esta segunda etapa se caracterizou pela permanência da população dos desmobilizados do exército em fazendas com áreas delimitadas. Este ciclo representou o primeiro ato de

\footnotetext{
${ }^{4}$ Trabalho realizado no campo, termo geralmente usado para se referir ao trabalho com a criação de gado.

5 A Guerra do Paraguai foi o maior e mais sangrento conflito armado que ocorreu em solo americano. Estendeu-se desde dezembro de 1864 até março de 1870. Denominada de Guerra da Tríplice Aliança (Brasil, Argentina e Uruguai - financiados pela Inglaterra), os conflitos transformaram o Paraguai em "terra arrasada".
} 
expulsão da terra que a comunidade terena passou a sofrer na sua trajetória por solo brasileiro.

O surgimento de fazendas é uma característica nova que passou a se configurar neste novo modelo de ocupação dos espaços. Cardoso de Oliveira (1968) afirma que as cercas delimitando o tamanho das propriedades tornaram-se fundamentais para disciplinar a ocupação dos territórios:

[...] surgimento de verdadeiras fazendas, já com características "modernas", pois constituídas de pastos delimitados por cercas de arame, indispensáveis a contenção dos rebanhos nas glebas de seus proprietários. [...] face ao aumento da população regional e, consequentemente, com o aparecimento de novos fazendeiros, a disciplinação dos territórios foi inevitável (CARDOSO DE OLIVEIRA, 1968, p. 41).

Com o aparecimento das cercas 6 instaurou-se a privatização da propriedade da terra e a partir daquele momento, então, a mão de obra indígena passou a fazer parte definitivamente da economia regional, sendo incorporada aos trabalhos das fazendas em condições muito semelhantes pelas quais passavam os remanescentes ou mesmo trabalhando como peões livres, porém presos por dívidas intermináveis contraídas junto aos proprietários das fazendas na compra de alimentos básicos. Desta forma, os indígenas foram expropriados de suas terras e passaram a trabalhar como peões nas áreas que antes Ihes pertenciam, desempenhando um trabalho semiescravo.

Vivendo nestas condições de expropriação/exploração é que o povo Terena estabeleceu o contato com a população não índia. No entanto, desde o primeiro contato eles já foram colocados como "seres inferiores", obrigados a uma condição de trabalho e de vida miseráveis.

Desde o início do processo de luta por demarcação das terras originárias, todos os dias, as emissoras de televisão regionais e estaduais disseminam o ódio aos

\footnotetext{
${ }^{6}$ Os cercamentos, conforme nos aponta Marx (1985) em $O$ Capital, são processos de exclusão dos trabalhadores de seus meios de sustento, de suas terras produtivas, que são transformadas em propriedades privadas, obrigando os trabalhadores a vender a sua força de trabalho em troca de um salário. Embora não se aplique linearmente a situação do Brasil ao caso europeu, cremos que, no bojo das discussões, o termo "cercar" é o que melhor representa a situação/fato. Para maior aprofundamento/entendimento, ver $O$ Capital, Volume I, "Parte VI A chamada acumulação primitiva", 1985.
} 
índios. Em quase todas as notícias relacionadas com o tema, os indígenas aparecem como os "invasores", os "vagabundos", os que querem "impedir o progresso", os "selvagens" que não precisam de terras porque não trabalham (TAVARES, 2013, n.p.).

Os Terena desempenhavam as mais variadas atividades produtivas nessa região, desde a extração da casca de angico (rica em tanino, usado na curtição do couro) - atividade na qual tinham extrema habilidade para extrair sem machucar a planta - até as atividades relacionadas com a criação de gado e plantação das lavouras.

Em função da Guerra do Paraguai, as aldeias encontravam-se destruídas, a população indígena desorganizada e refugiada nas regiões de mais difícil acesso. Com o fim do conflito, verifica-se que não ocorreu o retorno dos índios para as suas terras e aldeias de origem, já que muitas delas haviam sido destruídas e queimadas pelo inimigo. Desse modo, dispersa, a população vinculou-se ao trabalho nas fazendas em condições precárias, conforme já estavam submetidos os antigos escravos. No trabalho, a população indígena perdeu, ao longo dos anos, a sua identidade cultural, chegando, inclusive, a perder até mesmo os seus próprios nomes, passando a usar os nomes dos patrões ou de alguma personalidade não índia que por lá havia passado durante esse período.

Após o final da Guerra, e com a ocupação da região por grandes fazendeiros e também pela implantação das colônias agrícolas por iniciativa governamental, teve início o terceiro ciclo de povoamento que coincidiu com a construção da estrada de ferro ligando Bauru/SP a Porto Esperança/MT7 (1905-1908) e com a criação do Serviço de Proteção aos Índios (SPI), no ano de 1910. Conforme Cardoso de Oliveira (1968), neste período, ocorreu a criação das Reservas Indígenas, através de ações governamentais, tentando-se reunir as famílias terena que se encontravam dispersas pela região em função da Guerra e trabalhando como trabalhadores "sem-terra" nas fazendas que por ali foram se formando.

Importante enfatizar que a criação das reservas indígenas é um paradoxo, pois, se de um lado, se apresentava com a justificativa de

\footnotetext{
${ }^{7}$ Nesta época, ainda não havia ocorrido a divisão do Estado de Mato Grosso, o que só ocorreu no ano de 1979, atualmente Porto Esperança situa-se no Estado de Mato Grosso do Sul.
} 
"proteger" as populações indígenas, por outro, eram/são confinados em reservas minúsculas, eles que antes tinham a liberdade de se deslocar por toda extensão da área para produzir a própria existência e manter ritos próprios de sua cultura. Com a criação das reservas estariam "protegidos", permitindo-se, assim, a formação de grandes latifúndios. De fato, podemos afirmar que a criação das reservas indígenas foi mais um ato de expulsão da terra praticado contra estes povos para dar lugar ao avanço do capital, aqui simbolizado pelas grandes fazendas agropecuárias.

Esta foi a "visão de progresso" que passou a ser defendida, pois tudo o que impedia o avanço do capital precisava ser destruído, florestas, rios, ou até mesmo seres humanos. Com este objetivo, a exploração econômica avançava sobre as florestas e sobre os povos que lá viviam, destruindo-os, escravizando-os, humilhando-os e utilizandoos como mão de obra para o capital.

Com a formação de grandes latifúndios e em nome da modernização da agricultura, os índios foram expulsos de suas terras, obrigados a abandonar o lugar que tradicionalmente habitavam já há muitos anos, e foram transferidos para pequenas reservas criadas pelo governo.

Nessa época, forçados a permanecer nas reservas indígenas, insuficientes para o sustento da população da aldeia, os Terena, acostumados com a plantação de suas lavouras de subsistência, se viam obrigados a continuar buscando trabalho nas fazendas da redondeza. Muitos procuraram trabalho no corte da cana-de-açúcar, na colheita de semente do capim braquiária, ou mesmo em outras atividades agropecuárias, ou até mesmo algum tipo de trabalho nas cidades vizinhas, para auxiliar no sustento de suas famílias, nestes casos, trabalhos que não exigissem qualificação e, consequentemente, com salários reduzidos. Ao assumirem esse tipo de trabalho temporário, em fazendas da região ou até mesmo em cidades mais próximas, geralmente em períodos de safra ou de plantação, chegavam a ficar meses fora de casa. Vivendo em condições de expropriação e exploração, longe do convívio com seus familiares, lembramos Marx, quando afirmava que: 
[...] na produção social de sua existência, os homens estabelecem relações determinadas, necessárias, independentes da sua vontade, relações de produção que correspondem a um determinado grau de desenvolvimento das forças produtivas materiais. 0 conjunto dessas relações de produção constitui a estrutura econômica da sociedade, a base concreta sobre a qual se eleva uma superestrutura jurídica e política e à qual correspondem determinadas formas de consciência social. O modo de produção da vida material condiciona o desenvolvimento da vida social, política e intelectual em geral. Não é a consciência dos homens que determina o seu ser; é o seu ser social que, inversamente, determina a sua consciência (MARX, 1973, p. 28).

Nesse sentido, a população indígena terena, expulsa de suas terras tradicionais pelo processo de expansão do capitalismo e pela modernização da agricultura e da pecuária, se vê obrigada a viver nas reservas minúsculas em que foram confinados, cercados por latifúndios ${ }^{8}$. Diante deste cenário, que perspectivas Ihes restariam?

Martins (1993) fala da retirada dos camponeses de suas terras para dar lugar ao avanço do capital e assim dar um uso capitalista para a terra, um uso moderno e racional. No entanto, lembra também que, para concretizar este modelo de agricultura, a força de trabalho dos camponeses era fundamental, porém "como operários, como assalariados, vendedores de força de trabalho, portanto, como donos de mercadorias, como equivalentes de mercadoria" (MARTINS, 1993, p. 30). Foi exatamente isso o que aconteceu com os povos indígenas que viviam naquela região. Perderam suas terras e passaram a trabalhar para os donos do capital, vendendo aquilo que lhes restava, a sua força de trabalho. Ao serem jogados no mercado do trabalho e da exploração, adultos e crianças são alijados de seus sonhos, ou, como afirma Martins, esta situação a qual estavam submetidos "mata o sonho e a esperança e antecipa cruelmente o futuro como momento de carência e brutalidade sem remédio" (MARTINS, 1993, p.14).

Foi devido à situação a que foram colocados os índios Terena, pelo avanço do capital sobre suas terras, que fez com que fosse

\footnotetext{
${ }^{8}$ Este processo de expropriação/exploração pelo projeto do capital em terras indígenas não se dá de modo pacífico. Pelo contrário, ocorre na luta pelo retorno à terra, ou seja, para se reproduzirem enquanto povo.
} 
necessária a busca por novos meios de sobrevivência distante de seus parentes. Assim, inicia-se uma nova fase na história de batalhas deste grupo indígena. Inicia-se o período de luta efetiva pela conquista de um espaço próprio onde fosse possível construir uma nova história.

\section{A conquista da nova terra}

Me sentia muito triste porque nós estávamos brigando por uma terra, assim, e nós não tínhamos uma terra (GESAIAS, criança indígena, 10 anos).

$\mathrm{Na}$ queda de braço entre proprietários de terra e indígenas, raramente os indígenas saem vencedores. Roubados de suas terras desde a invasão em 1500, sistematicamente os povos originários foram sendo atacados, dizimados e humilhados (TAVARES, 2013, n.p.).

A condição de índios com pouca terra, confinados em pequenas reservas, levou-os à constatação de que o espaço físico onde viviam era demasiadamente reduzido para a sobrevivência do grupo, e este foi um dos principais motivos que fizeram com que essas famílias se submetessem à migração definitiva para longe de suas terras e de seus parentes, em busca de melhores condições objetivas para se reproduzirem enquanto uma nação, enquanto um povo.

Encontramos os elementos que motivaram a busca por uma nova terra para este grupo, oriundo da comunidade Terena de Buriti ${ }^{9}$, na história de vida do pioneiro, o Senhor Hélio Turi Rondon, importante lutador para a sobrevivência da comunidade (ISSAC, 2004).

O Senhor Hélio Turi Rondon era descendente dos índios Tapirapé, nascido na Ilha do Bananal, no nordeste do Estado de Mato Grosso e ainda criança saiu daquela região acompanhando a expedição do Marechal Cândido Rondon. Anos mais tarde foi para o Rio de Janeiro, onde estudou em uma escola agrícola. Depois de rapaz, foi servir no Exército Brasileiro e no exercício do serviço militar foi para a cidade de

\footnotetext{
${ }^{9}$ A Terra Indígena Buriti está localizada no município de Dois Irmãos do Buriti, no Estado de Mato Grosso do Sul. Possui área de 2090 ha e uma população de 1.783 índios, segundo dados oficiais da Fundação Nacional do Índio (Funai) em 2002. Este número era contestado pelos índios, que afirmavam serem mais de 2500 índios nesta terra.
} 
Campo Grande/MS. Neste período deslocou-se para a aldeia Buriti. Lá encontrou a comunidade Terena e conheceu sua futura esposa, a Senhora Catarina Jorge. Casaram-se e constituíram seu grupo familiar.

Aliado às precárias condições em que viviam na aldeia, estava a penosa rotina de atividades nas fazendas que necessitavam se submeter para conseguir o seu sustento. Para este trabalho muitas vezes deslocavam-se famílias inteiras das aldeias para trabalhar nas fazendas, e, a mão de obra infantil era amplamente usada na execução destas tarefas, sem se importar muito com os problemas de saúde que este tipo de trabalho acarretava. No entanto, devido às péssimas condições de vida as quais estavam submetidos, e sem ver outras possibilidades de sobrevivência, viam-se obrigados a trabalhar para ajudar no sustento das famílias e, com isso, o tempo de ser criança era substituído pelo trabalho infantil.

As dificuldades enfrentadas pela falta de terra e de assistência, aliada às questões familiares de morte de dois filhos, além das questões graves de saúde que estavam atingindo a aldeia, crianças com verminose e fome, contribuíam para que o Senhor Hélio Turi Rondon relembrasse com saudade de sua infância na aldeia tapirapé, no Estado de Mato Grosso, onde existia muita fartura, muita terra, muita mata, muita caça, grandes rios com muito peixe, como o Rio Araguaia, e resolvesse lutar por uma nova área de terra para seu povo. Segundo Milton Rondon (entrevista em 03 de novembro de 2007), seu pai lembrava da fartura que tinha na infância e sempre comentava com seus filhos o seu desejo: "um dia a gente volta pra lá!".

Fugir dessa situação de expropriação e de abandono a qual estavam submetidos pelas diversas formas de exploração impostas pelo capital, negando-lhes qualquer possibilidade de conseguir uma vida digna, tornando-os objeto de mínimo valor, era visto como única solução para aquele povo.

\section{A vida nas novas aldeias em Mato Grosso}

Viemos de ônibus, foi contratado ônibus, nós tínhamos caminhão já também, que a Funai comprou, porque quando nós aceitamos vir pra cá, a Funai falou: não, 
nós vamos dar dinheiro pra vocês e aí foi rapidinho. E - ministério da justiça disse: desde que seja para mudar daqui, já foi rapidinho. 6 ônibus, 5 ônibus, caminhão, trouxe todas as coisas nossas. Foi rapidinho, de um dia para outro, aí nós tínhamos que alugar casa, arrumar barraco. Seis meses nós moramos, nós moramos em barraco (Cirenio, Liderança indígena, entrevista em 07 de agosto de 2007).

Em meados de janeiro de 2003, o grupo Terena, liderado pelos caciques Milton Rondon e Cirenio Reginaldo, após passar anos acampados e realizando diversos protestos na região de Rondonópolis, chegou ao norte de Mato Grosso e criou a aldeia Kopenoty, no município de Peixoto de Azevedo e, posteriormente, foram criadas as aldeias Turipoku, KoxonetyPoke'é e Imanaty. Essas três últimas na Terra Indígena Terena do Iriri, que abrange os municípios de Peixoto de Azevedo e Matupá. A partir daí inicia-se um novo capítulo na história deste povo.

Instalados nas novas aldeias, começou a ser possível reestruturar a vida comunitária. A escola teve um papel fundamental nesse processo, pois foi a partir dela que as ações mais importantes começaram a ganhar força, principalmente na reativação das práticas culturais.

A terra conquistada num processo de lutas representa a possibilidade de pensar e planejar o futuro do grupo e a tranquilidade para criar e educar as crianças. Ao comparar a vida das crianças após dez anos da chegada nesta nova terra com o tempo em que viviam na Aldeia de Buriti no Mato Grosso do Sul, Dona Catarina Jorge ${ }^{10}$ demonstra alegria e satisfação por esta nova realidade que as crianças estão vivendo e assim se expressa:

Hoje estão feliz, né. Nessa época, agora, tão feliz porque agora não falta um remédio pra eles. Aquele tempo, remédio nosso era só do mato mesmo, não tinha doutor, não tinha médico, não tinha nada. Era só as coisa do mato. Ficou doente, vai no mato arrancar uma folha e ferve, dar para a criança tomar. Dá para criança se banhar. E, agora não. Ficou doente, corre lá

\footnotetext{
${ }^{10}$ Dona Catarina pode ser considerada a matriarca deste grupo Terena de Mato Grosso, ela é viúva do Senhor Hélio Turi Rondon.
} 
no doutor (Dona Catarina, anciã indígena, em entrevista realizada no dia 19 de abril de 2008).

No que se refere à situação das crianças na aldeia Kopenoty, temos também a fala de Alvanei, índio Terena da aldeia Kopenoty e acadêmico do curso de enfermagem na UFMT/Sinop, que exalta a alegria das crianças com a vida que estão tendo na nova aldeia e com a possibilidade de melhorar ainda mais essas condições e ampliar as possibilidades que se apresentam a partir da conquista da terra.

[...] a gente pode perceber que, hoje, eles estão mais contentes com a realidade que eles viveram durante todo esse tempo de lutas e protestos. Eu acho que o que os torna, hoje, mais felizes, é eles poderem ter um lugar para eles morar. Então, hoje, a gente vê as crianças tendo um teto, uma casa para eles morar. Assim, em termos da realidade que a gente viveu na época dos protestos, que eram barracos de lona, na época da chuva, era aquela angústia. Então, o fato de não terem uma segurança, às vezes, vinha o vento, a chuva, ou alguma coisa assim, então era difícil para eles. Mas, hoje, o que a gente vê eles mais felizes. Hoje, é justamente por essa causa de eles poderem ter um lugar para ficar, eles se sentem mais seguros com relação a uma localidade própria deles. Eles, numa reserva, tem uma casa mais adequada do que a que eles viveram durante aqueles anos. Então, acho que isso torna eles mais felizes. A gente vê que eles estão mais felizes hoje. Tem uma escola mais adequada do que a realidade que eles viveram no passado. Acho que isso torna as crianças mais diferentes, nesse sentido (Alvanei, Liderança indígena, entrevista no dia 31 de agosto de $2007^{11}$ ).

A diferença entre a situação atual e a anterior é que lá no Mato Grosso da Sul o crescimento das famílias e dos filhos gerava uma escala de necessidades que não podia ser atendida pelo trabalho e pelas condições da reserva. Enquanto que a reserva do Iriri agora pode possibilitar uma condição de vida e de sustentabilidade para todo o povo, pois nessa nova terra têm a possibilidade de plantar, colher,

\footnotetext{
${ }^{11}$ Destacamos que nesse ano de 2007 o Alvanei iniciou o curso de Enfermagem na Universidade Federal de Mato Grosso. Concluiu seu curso no primeiro semestre de 2013 e está trabalhando na aldeia. A partir de 2008 outros jovens indígenas passaram a ingressar na UFMT, nos cursos de Enfermagem, Engenharia Florestal, dentre outros.
} 
caçar, pescar, enfim, garantir a sustentabilidade do povo a partir do seu trabalho.

Apesar do tempo que nos separa de Marx e Engels (2002), podemos afirmar que este povo estava lutando para a satisfação das primeiras necessidades, da busca pelo primeiro pressuposto para a existência humana, assim como fora apontado pelos autores:

[...] o de que todos os homens devem ter condições de viver para poder 'fazer a história'. Mas, para viver, é preciso antes de tudo beber, comer, morar, vestir-se e algumas outras coisas mais. O primeiro fato histórico é, portanto, a produção dos meios que permitem satisfazer essas necessidades, a produção da própria vida material; e isso mesmo constitui um fato histórico, uma condição fundamental de toda a história que se deve, ainda hoje como há milhares de anos, preencher dia a dia, hora a hora, simplesmente para manter os homens com vida (MARX e ENGELS, 2002, p. 21).

A luta que os Terena se propuseram a enfrentar era para conseguir o básico, ter um pedaço de chão para tentar garantir em primeiro lugar a sobrevivência, garantir o mínimo para só então poder almejar melhores condições de vida e de produção de cultura. Nas pesquisas que realizamos, a questão econômica é colocada a todo o momento como uma das principais causas para a saída deste grupo do Mato Grosso do Sul e percebemos que hoje, com a possibilidade de produção de uma agricultura básica e produzindo inclusive excedentes, essa preocupação cede espaço para outras necessidades, como podemos perceber nas conversas com alguns membros do grupo realizadas neste ano de 2013, quando completa-se 10 anos da conquista deste território.

Aqui tá bom, né. Viemos do Mato Grosso do Sul e aqui temos um espaço pra plantar. Nesses 10 anos, nós estamos bem aqui. Os guris estão trabalhando, gostaram daqui. Um pouco fica aqui na Aldeia Kopenoty, um pouco vai pro mato, lá para reserva do Iriri (Dona Catarina, conversa em 19 de abrir de 2013).

A satisfação com essa nova realidade é facilmente percebida na fala de Dona Catarina, e também dos demais membros desta 
comunidade, pois a conquista da terra possibilitou muitos avanços, não apenas na questão econômica, mas também na vida social e cultural da aldeia.

De 2003 até 2007 ainda permanecia um impasse na demarcação da terra, então ainda existia uma insegurança, pois a demarcação ainda não estava realizada pelo Instituto Nacional de Colonização e Reforma Agráfia (Incra). Foi iniciada uma produção, mas apenas em um pequeno pedaço de terra onde foi instalada a primeira aldeia, a Aldeia Kopenoty, mas ainda não estava de acordo com aquilo que se esperava.

Aqui na aldeia Kopenoty se criou uma estrutura boa de casas, escola, posto de saúde. A partir de 2007, começamos a mexer com roças lá na reserva, nas aldeias KoxonetyPoke 'é e Toripoku e, com isso, já teve uma expectativa de vida melhor. Enquanto estávamos só aqui na Kopenoty, o pessoal ficava muito parado, não tinha trabalho para todo mundo. Aí, lá tem trabalho, tem pesca, caça, roça. Depois, outros projetos começaram a ser desenvolvidos na reserva como o projeto da coleta de sementes que ajudou o pessoal a trabalhar na área e a pensar na questão ambiental, no reflorestamento, preservar a área nativa e trabalhar apenas na área que estava derrubada (Matheus, conversa no dia 19 de abril de 2013).

Algumas dificuldades também foram encontradas nessa nova etapa da vida do povo Terena de Mato Grosso, uma delas foi a adaptação a essa nova terra, que é diferente do ecossistema do cerrado do qual vieram e no qual estavam acostumados a trabalhar. Aliado a isso, destacamos ainda a falta maquinários, ferramentas e até mesmo conhecimentos básicos para trabalhar nessa nova realidade, cujo bioma é Floresta Amazônica. Nem as madeiras que encontravam na floresta eram conhecidas por esse povo. Entretanto, no depoimento de Matheus, há aprendizagens importantes para a produção da nova vida:

Com os novos conhecimentos, e com o trabalho de coleta de sementes, passamos a fazer artesanato. Estamos trabalhando com a revitalização da nossa cultura, e também na diversificação do plantio de outros tipos de sementes, variedades de mandioca, banana, cará e outros produtos que ajudam na alimentação do povo (Matheus, conversa no dia 19 de abril de 2013). 
Desta forma, consideramos que nesta nova terra houve muitos avanços, principalmente na questão econômica, o pessoal passou a ter mais possibilidades de se sustentar a partir de suas próprias plantações. Já conseguem produzir muitos alimentos para o consumo próprio. Com a possibilidade de plantar, colher, caçar, pescar e viver seus rituais característicos da cultura terena, o sentido de autonomia passa a fazer parte de suas vidas. A humilhante espera da chegada das cestas básicas ofertadas pelo governo, dadas as condições de precariedade que viviam, passa a ser substituída pela alegria de produzir a vida e a cultura no jeito próprio de ser. Embora perceba-se que no processo migratório vivido por este coletivo muitas perdas foram sentidas, destacadamente aquelas relativas à questão cultural.

Os principais problemas que identificamos nesse período continuam sendo aqueles com relação à saúde, falta de saneamento básico e cuidados principalmente com relação ao uso da água. Outro problema é a questão ambiental; identificamos nas conversas que há uma pressão muito grande do entorno sobre a área indígena. Existe uma pressão de empresas grandes, multinacionais, que fazem propostas para a exploração da área indígena, exploração de madeira e também de minérios, e os indígenas reclamam que não estão sabendo lidar com esta situação.

Existe ainda muita madeira grande na reserva. É uma área intacta, então, tem muita madeira. Também possui minério na área e a pressão está realmente grande. Contamos com nossas lideranças para resistir, mas sabemos que é difícil e acreditamos que nem a Funai conseguirá segurar isso (Matheus, conversa no dia 19 de abril de 2013).

A relação com os povos vizinhos, os Panará e os Caiapó, também merece destaque. Os Terena, que no início não teriam sido bem recebidos por esses "parentes", como eles mesmos se tratam, estão fortalecendo as relações com os demais povos a cada dia, percebemos a presença de membros Caiapó e Panará constantemente entre os Terena, o que tem melhorado muito o trabalho destes grupos.

Outro problema levantado foi com relação aos conhecimentos tradicionais, principalmente no que diz respeito às ervas medicinais que 
eram conhecidas no sul, pois nesta nova terra as plantas são completamente diferentes das que conheciam no Mato Grosso do Sul e para entender essa nova realidade contam com os parentes Caiapó e Panará, que estão ajudando na identificação destas ervas.

[...] antes, não éramos bem-vindos aqui. Eles não confiavam em nós. Agora eles vem dançam com a gente, estão na escola, participam das festas, nos convidam também para participar da aldeia deles. Consideramos que é uma relação de amizade e, ao mesmo tempo, de conquista. Já são cerca de 3 anos que as aldeias mesmo vêm participar da nossa festa e também eles têm nos ajudado muito para conhecer essa região, essas plantas, principalmente as ervas medicinais (Matheus, conversa no dia 19 de abril de 2013).

As festas realizadas nas aldeias terena têm motivado os Panará e os Caiapó a valorizar e realizar festas tradicionais em suas aldeias também, como Matheus nos destaca.

A língua materna, praticamente falada apenas por algumas pessoas de mais idade, tem sido uma preocupação grande para os professores da aldeia e tem sido um tema sempre discutido na escola, como destaca Juarez,

A língua materna é uma preocupação enquanto professor, e buscamos estratégias pra ajudar as crianças a aprender e acreditamos que não tem lugar melhor do que dentro da nossa casa. Essa é uma questão que vem preocupando a gente, principalmente com a chegada desses parentes que estão vivendo dentro das nossas aldeias. Precisamos elaborar materiais didáticos para trabalhar dentro das salas de aula que valorizem a nossa cultura. Ir ao encontro de nossos idosos que ainda falam fluentemente a língua materna e levá-los para escola. A língua é uma identidade para os Terena, não pode ser esquecida. Entendemos que o processo que vivemos de lutas, até chegar aqui, contribuiu muito para que a língua fosse deixada de lado, principalmente pelas crianças (Juarez, em conversa no dia 19 de abril de 2013).

O cacique Milton também destaca que a saúde é um dos grandes problemas enfrentados pela população indígena, embora afirme que 
entre os Terena a situação ainda está melhor, mas com os parentes a situação é grave. Afirma que mortalidade infantil entre os Panará é muito grande, por anemia, má alimentação e falta de assistência por parte dos órgãos governamentais. Nas aldeias terena existe um trabalho dos agentes de saúde, juntamente com a comunidade, buscando prevenir as doenças, preocupados para tratar as pessoas antes de ir para o hospital, cuidando principalmente da alimentação, "nosso povo está se alimentando bem, estão gordinhos" afirma o cacique Milton.

Retratando os problemas que enfrentam na reserva, Milton afirma que há preocupação em relação ao transporte da produção e à comercialização do excedente, que começa a acontecer, e relembra que a agricultura é a vocação dos Terena:

Nós sempre sonhamos em ser produtores. Os Terena
tem isso desde sua origem e aqui estamos conseguindo
realizar esse sonho, apesar das dificuldades que ainda
encontramos. Nesses 10 anos talvez ainda não
produzimos aquilo que esperávamos, acreditávamos
que poderíamos estar produzindo muito mais, demorou
muito para iniciarmos as plantações e agora que
estamos tirando os pés do chão (Milton, conversa no
dia 19 de abril de 2013).

Desta forma, a conquista da terra representa um grande avanço para este povo, conforme completa Milton:

Para nós é uma grande conquista estar aqui no Mato Grosso. Essa integração com os outros povos como os caiapó, panará e com a população não índia, então isso para nós representa uma grande conquista (Milton, conversa no dia 19 de abril de 2013).

A integração do povo Terena com os demais povos indígenas e também com a comunidade do entorno também foi um dos aspectos que nos chamou a atenção em nossas visitas de pesquisa e, principalmente, nos momentos em que éramos convidados e íamos acompanhar as festas realizadas na aldeia, sempre marcada por grande presença de público que prestigiavam as apresentações culturais.

\section{Considerações finais}


Uma das considerações que gostaríamos de destacar aqui neste texto - e que ficou evidente em nossas pesquisas - é que a conquista da terra foi fundamental para que todos os outros avanços acontecessem. A posse da terra representa a possibilidade de pensar e planejar ações futuras. Permite, ainda, retomar as principais atividades deste povo, como a prática da agricultura, e ajuda na recuperação das práticas culturais, pois, instalados numa terra definitiva, a luta passa a ter novos objetivos e é nesse ponto que a escola passa a desempenhar um papel fundamental na vida da comunidade. A escola passa a ser o elo de encontro entre o povo e sua cultura, sua língua e seus conhecimentos tradicionais.

Neste aspecto, a formação dos professores tem ajudado muito. Vários deles concluíram ou estão cursando o $3^{\circ} \mathrm{Grau}$ Indígena na Universidade do Estado de Mato Grosso. Essa formação contribui na melhoria das práticas pedagógicas nas salas de aula e, consequentemente, reflete em melhorias para toda a comunidade.

Alguns Terena estão cursando faculdade em Sinop, na Universidade Federal de Mato Grosso, através do Programa de Apoio à Formação Superior e Licenciaturas Interculturais Indígenas (Prolind), que em 2013 formou o primeiro acadêmico no curso de Enfermagem e que contribuirá significativamente para ajudar a sanar uma das principais dificuldades da aldeia, que é a questão da saúde.

Para concluir, destacamos que nesses dez anos em solo matogrossense muitos avanços aconteceram; porém ainda há um caminho de lutas que precisa ser continuado, pois os desafios ainda são grandes e muitos aspectos ainda precisam ser conquistados, e só a organização e a luta poderão garantir os direitos que lhes são assegurados. Destacamos, ainda, o papel importante que a escola terena tem assumido como articuladora da vida comunitária, condição de acesso ao saber, e na revitalização da cultura terena.

\section{Referências bibliográficas}


CARDOSO DE OLIVEIRA, Roberto. Urbanização e Tribalismo: a integração dos índios Terena numa sociedade de classes. Rio de Janeiro: Zahar Editores, 1968.

Do índio ao bugre: o processo de assimilação dos Terena. Rio de Janeiro: Francisco Alves, 1976.

ISAAC, Paulo A. M. Modo de existir Terena na comunidade multiétnica que vive em Mato Grosso. 2004. 317 f. Tese (Doutorado em Ciências Sociais) - Pontifícia Universidade Católica de São Paulo, [2004].

MARTINS, José de Sousa. O massacre dos inocentes: a criança sem infância no Brasil. São Paulo: Hucitec, 1993.

Exclusão social e a Nova Desigualdade. São Paulo: Paulus, 1997.

MARX, Karl. Contribuição para a crítica da economia política. Lisboa: Estampa, 1973.

.O Capital. São Paulo: Nova Cultural, 1985. v. 1.

MARX, Karl; ENGELS, Friedrich. A Ideologia Alemã. São Paulo: Martins Fontes, 2002.

TAVARES, Elaine. Governo suspende demarcação de terras indígenas no sul do Brasil. Brasil de Fato. Disponível em: http://www.brasildefato.com.br/node/26517. Acesso em: nov. 2013.

ZOIA, Alceu. A Comunidade Indígena Terena do Norte de Mato Grosso: infância, identidade e educação. 2009. 244 f. Tese (Doutorado em Educação) - Faculdade de Educação, Programa de Pós-Graduação em Educação, Universidade Federal de Goiás, Goiânia, [2009].

Recebido em: 29/01/2015 * Aprovado em: 02/05/2015 * Publicado em: 30/06/2015 